\title{
Walter Benjamin, la crítica a la modernidad: el arte de la desconfianza
}

\author{
Helena Chávez Mac Gregor
}

\section{Introducción}

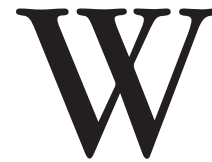

alter Benjamin fue uno de los críticos más grandes de la modernidad. Sin embargo, habrá que notar que en el filósofo esto supone a la vez una continuidad y una ruptura. Benjamin partió de los planteamientos de la modernidad, en específico los postulados por Kant, para realizar una crítica a la experiencia. En esta categoría el filósofo encontró uno de los problemas centrales de su tiempo, una capacidad empobrecida que alienaba al sujeto y lo sumergía en formas arcaicas, generando una especie de ensoñación y pasmo.

En este sentido, si bien Benjamin exploró las posibilidades críticas de la experiencia no se puede plantear que su crítica suponga un momento de superación. Lo interesante, creemos, es cómo logró movilizar ciertos planteamientos de la Ilustración para volver a invocar las posibilidades críticas de su discurso y, desde allí, pensar en cómo enlazar experiencia, arte, emancipación y revolución.

De todos es bien conocida la función revolucionaria que Benjamin encontró en el arte, pero lo que pretende este texto es examinar los posibles políticos que se abren desde el enlazamiento con la crítica a la experiencia que propuso. ${ }^{1}$ Además del momento de politización, como está expuesto en "La

${ }^{1}$ El momento más claramente revolucionario del arte en el pensamiento de Benjamin se encuentra en el texto "La obra de arte en su época de la reproductibilidad técnica" donde a partir de la exploración de la trasformación técnica del arte, Benjamin supo no sólo cuestionar a la tradición que mantenía la función del arte en el culto y el ritual sino que, a partir de esa crítica, pudo plantear la transformación de la estética, como experiencia, a partir del propio sistema de aparatos. Si bien Benjamin ya veía una función revolucionaria en el cine por la transformación de la percepción que generó, éste propone que para pensar en su politización tendría que rebasar este punto y llevar la 
obra de arte en la época de la reproductibilidad técnica", Benjamin exploró una potencia política en el arte cercana a una experiencia de emancipación estética y epistemológica.

Es claro que esta pretensión se encontraba inscrita en los propios fundamentos de la estética como fue planteada por la Ilustración. El propio Kant encontró en la experiencia estética la posibilidad de un común desde la suposición de la igualdad, donde ni la educación, ni la clase, ni el conocimiento limitaban la posibilidad de participar en el juicio de lo bello, que tenía que ser necesario y universal para poder se considerado como tal. Generando un tipo de experiencia que, más allá de la propia descripción de la operación del juicio de gusto, potencializaría un común. ${ }^{2}$

En este sentido, si bien es interesante que Benjamin propone una revisión a la noción de experiencia desde el empobrecimiento de ésta por parte de la Ilustración, no deja de ser importante subrayar que su crítica retomó uno de los campos, el arte, que el propio pensamiento ilustrado abrió para asegurar una forma de experiencia, sí racional y dentro de los propios límites del sujeto, pero que se supondría una posibilidad para la emancipación.

Sin duda, una de las líneas de trabajo más fructíferas, y todavía en exploración, del filósofo alemán es justamente la que tiene que ver con la estética. Benjamin encuentra en el arte no sólo la politización desde el aparato estético que vuelve a la masa su radicalidad desde un sensorium nuevo, sino la posibilidad de una experiencia emancipatoria donde la desconfianza produce un desencanto desde la que se abre una revolución "copernicana". En este sentido, creemos que es posible leer en la crítica de Benjamin a la modernidad una noción de experiencia que invoca no sólo a una alianza revolucionaria-como

propia especificidad del sistema de aparatos a la crítica de las condiciones de la propiedad, señalando así una posibilidad de ruptura donde el aparato funciona como crítica y no como ideología.

${ }^{2}$ No es el espacio aquí para desarrollar esta idea pero es importante señalar esta relación entre la estética y la emancipación. Autores contemporáneos como Jacques Rancière han encontrado en este nudo una de las paradojas que mantienen a la estética como un régimen de lo sensible que permite identificar objetos, modos de experiencia y de pensamiento desde una promesa por una comunidad de iguales que, a la vez que mantiene una esfera de autonomía es capaz de intervenir en la vida. Esta contradicción mantiene la pregunta por la posibilidades políticas del arte. En este sentido es interesante subrayar lo que señala Rancière: "¿Por qué esta suspensión funda en sí misma un nuevo arte de vivir, una nueva forma de la vida en común? En otras palabras, ¿por qué una cierta "política" es consustancial con la definición misma de la especificidad del arte dentro de ese régimen? La respuesta, en su forma más general, se enuncia de la siguiente manera: porque define los objetos del arte por su pertenencia a un sensorium diferente al de la dominación. En el análisis kantiano, el libre juego y la libre apariencia suspenden el poder de la forma sobre la materia, de la inteligencia sobre la sensibilidad" (Jacques Rancière, El malestar en la estética. Buenos Aires, Capital Intelectual, 2011, p. 42). 
está expuesta en "la obra de arte en la época de su reproductibilidad técnica" o en "El autor como productor" - sino también a un momento de intoxicación, pesimismo y desencanto que activa una ruptura que es tanto estética como política. Es sobre esa línea que trabajará este texto.

\section{Experiencia y shock}

Hay en el pensamiento benjamineano una interesante relación con los planteamientos kantianos que, sin duda, fueron decisivos para su revisión de la noción de experiencia. Es claro que el contexto de la tradición filosófica de corte neokantiano en la que estudió, así como su cercana relación al Die deutsche Jugendbewegung que encabezó Gustav Wyneken, despertó una investigación en las que el autor ligó aspectos pedagógicos y metafísicos. En textos entre 1912 y 1918 hay una reflexión sobre la herencia kantiana y el programa que la filosofía futura tendría que tener en su corrección epistemológica. Si bien en textos posteriores irá desapareciendo la referencia directa a Kant, es interesante pensar cómo estas reflexiones preliminares permitieron una revisión de la noción de experiencia que desencadenaría posiciones cada vez más complejas y arriesgadas.

En el texto "Sobre el programa de filosofía venidera", Benjamin planteó la necesidad de una revisión de los errores en la epistemología de Kant, que, según señala el texto, son rastreables en la vacía noción que la Ilustración tenía de la experiencia y que se puede entender por una ceguera religiosa e histórica de la época. El texto plantea la limitación del análisis de la experiencia por la pretensión de un conocimiento verdadero que perdió de vista la importancia de la experiencia pasajera y singular. En este sentido, Benjamin afirma:

El impedimento más significativo para la integración de una filosofía verdaderamente consciente de tiempo y eternidad en Kant es el siguiente: la realidad, a partir de cuyo conocimiento Kant quiso fundar el conocimiento en general sobre certeza y verdad, es una realidad de rango inferior, si no la más inferior de todas. El problema de la teoría del conocimiento kantiana, como sucede con toda teoría del conocimiento, tiene dos aspectos y sólo uno de éstos supo aclarar. En primer lugar, existe la cuestión de la certeza del conocimiento duradero; en segundo lugar, se plantea la cuestión de la dignidad de una experiencia pasajera. Y es que el interés filosófico universal está centrado simultáneamente en la vigencia intemporal del conocimiento, así como en la certeza de una experiencia temporal que es percibida como objeto más cercano, si no único. Pero los filósofos, y Kant entre ellos, no 
fueron conscientes de la estructura global de semejante experiencia en su singularidad temporal. Dado que Kant quiso extraer al principio de la experiencia de las ciencias, y en especial de la física matemática, sobre todo en los Prolegómenos, también en la Crítica de la razón pura, la experiencia dejaba de ser idéntica al mundo de los objetos de la ciencia. Y aun si la experiencia hubiese sido para Kant lo que terminó siendo para los pensadores neokantianos, el concepto así identificado y determinado continuaría siendo el viejo concepto de experiencia, cuyo sello característico se refiere no sólo a la conciencia pura sino igualmente a la empírica. Y de eso mismo se trata; de la presentación de la experiencia llanamente primitiva y autoevidente que a Kant, como ser humano que compartió de alguna manera el horizonte de su época, pareció la única dada y posible. Esta experiencia singular era pues, como ya se insinuó, temporalmente limitada, y desde esa forma que de cierto modo comparte con toda experiencia, y que podemos en el sentido más pleno llamar concepción del mundo, fue la experiencia de la Ilustración. ${ }^{3}$

La revisión que propuso Benjamin no sólo analizaba críticamente las limitaciones del planteamiento kantiano, sino que planteó la necesidad de re-pensar el tipo de intensidades de otros campos como el arte, el derecho y la historia arrojarían a la experiencia. Esto, según el autor, permitiría, por un lado, mantener la necesidad de un análisis trascendental y no meramente empírico del conocimiento y, por el otro, lograría incorporar una experiencia rica en matices y temporalidades que tendría como consecuencia una noción más amplia de la historia que la que había desarrollado la Ilustración y que había devenido en una estructura de causalidad donde el tiempo sólo podía ser pensado como progreso.

Leer estos textos en relación con su obra posterior permite una serie de reverberaciones que si bien no pretenden condicionar sus argumentaciones, sí nos permiten ver la continuidad y persistencia de ciertos problemas. Muchos años después de este texto de juventud, y ciertamente con una transformación de pensamiento no sólo por la madurez sino por el tipo de producción que tuvo que generar ante la imposibilidad del acceso al mundo académico y la precariedad laboral que eso conllevó, Benjamin escribiría en $1939^{4}$ una

\footnotetext{
${ }^{3}$ Walter Benjamin, "Sobre el programa de la filosofía venidera", en http://revistareplicante.com/sobre-el-programa-de-la-filosofia-venidera. [Consulta: 24 de octubre de 2014.]

${ }^{4}$ Este texto es uno de los últimos escritos por Benjamin. El 4 de septiembre de 1939 Benjamin fue enviado a Neveres, campo de trabajo para inmigrantes alemanes. Es liberado de éste el 25 de noviembre de ese mismo año gracias a la insistencia de Gisele
} 
reflexión sobre la experiencia, a partir de la obra de Baudelaire, donde distinguiría entre dos tipos de experiencia: la "experiencia vivida" como Erlebnis y "hacer experiencia" como Erfahrung.

En Sobre algunos temas en Baudelaire lo que se plantea, de manera más urgente y más radical que antes -lo cual también nos indica la politicidad de su trabajo intelectual ante el inicio de la Segunda Guerra Mundial y el constante acoso que vivían disidentes y judíos-, es la crítica de la modernidad a partir de la reflexión de la experiencia empobrecida. Benjamin planteó que el hombre de siglo xx se conformó como individuo y sociedad desde la "experiencia vivida" dejando fuera esa otra experiencia, Erfahrung, que no sólo es vivencia, sino que implica un caminar, un atravesar y ser atravesado que sólo emerge a través del recuerdo. Ambas palabras se refieren a la experiencia, pero Erlebnis tiene un sentido limitado a la vivencia del tipo de conocimiento, es decir, a la experiencia que recoge lo acontecido como datos, como información que no es transmisible mediante la narración. Mientras Erfahrung se refiere a "hacer" experiencia, a llevarla, a portarla, a ser parte de ella como ella es parte de nosotros, pero en un sentido casi escondido, inconsciente.

Benjamin, apoyado en su lectura de Allende el principio del placer,, 5 texto de Freud que apareció en 1921 en el que se establece una correlación entre la memoria (en su forma inconsciente) y la conciencia, explica que el atesoramiento de las improntas perdurables como fundamento de la memoria es algo que se halla reservado a "otros sistemas" que son diferentes de la conciencia. Para Freud, nos dice Benjamin, la importancia de la conciencia no está en acoger datos mnemónicos sino en la función de servir de protección contra los estímulos. Benjamin afirma que:

La amenaza proveniente de esas energías es la amenaza de shocks. Cuanto más normal y corriente resulta el registro de shocks por parte de la conciencia menos se deberá temer un efecto traumático por parte de éstos. La teoría psicoanalítica trata de explicar la naturaleza de los shocks traumáticos "por la rotura de la protección contra estímulos".

Freund, Helen Hessel y Henri Hoppenot. Después de su retorno a París, Benjamin sólo tuvo tiempo de escribir las Tesis de filosofía de la historia, pues se prepararía para salir, en septiembre del año cuarenta, definitivamente de Europa hacia Estados Unidos por la vía de los Pirineos. Sin embargo, el escape fracasa por problemas de documentación en la frontera española y Benjamin se suicida el 26 de septiembre de 1940 en el puerto de Port-Bou.

${ }^{5}$ Que es la única lectura que seguimos, ya que no pretendemos más que entender el pensamiento de Benjamin en este contexto.

${ }^{6}$ W. Benjamin, "Sobre algunos temas en Baudelaire", en Ensayos escogidos. México, Ediciones Coyoacán, 2001, p. 12. 
Para Benjamin, el hecho de que la conciencia capte y detenga el shock es lo que permite que, al hecho que causa dicho shock, se le dé el carácter de experiencia vivida. Así afirma: "La función peculiar de defensa respecto a los shocks puede definirse en definitiva como la tarea de asignar al acontecimiento, a costa de la integridad de su contenido, un exacto puesto temporal en la conciencia. Tal sería el resultado último y mayor de la reflexión. Ésta convertiría al acontecimiento en una 'experiencia vivida'". ${ }^{7}$ Es tras este análisis que Benjamin encontrará uno de los papeles más importantes de la obra de arte en la modernidad, ser capaz de producir en su experiencia algo parecido a ese shock. Uno de los casos que le permiten explorar este tipo de poética que posibilita la integridad del acontecimiento será Baudelaire.

Baudelaire es el poeta maldito que grita y arremete en su poesía en contra de lo establecido, grita de espanto y hace de la palabra la lanza para abrir la herida, es el poeta que muestra la emergencia desde el abismo, que se sumerge en el spleen, en el taedium vitae que parece envolver a los hombres de la modernidad. Baudelaire desde el genio alegórico trastoca la experiencia vivida y habla de los hombres y de las ciudades, del choque del individuo con la multitud. En vano, nos previene Benjamin, buscaremos en Baudelaire una descripción de la población o de la ciudad; Baudelaire ha renunciado a éstas, y ello le ha permitido evocar a la una en la imagen de la otra. La presencia de la multitud es la que posibilita los shocks a los que se enfrenta Baudelaire, ésta es la que condiciona la percepción, el ritmo y el movimiento en que el hombre de la gran ciudad vive su vida.

Es interesante notar que cercanos a la argumentación de la transformación de la percepción del hombre moderno, están los planteamientos marxistas sobre la alienación de los sentidos. En el análisis de la producción y del consumo, como está expuesto en la Introducción general a la crítica política, hay un proceso tanto de objetivación - del sujeto- como de subjetivación - de la cosa- donde no sólo el hombre produce al objeto sino que éste produce al sujeto. ${ }^{8}$ Así, uno de los retos del marxismo será, según como lo plantea Terry

${ }^{7}$ Ibid., p. 13.

${ }^{8}$ Es posible pensar que hay al menos tres formas en que el marxismo reinscribe la condición de lo sensible, y al hacerlo abre la cuestión estética desde la propia pregunta por la producción material: el objeto y su transformación a partir del trabajo, el materialismo como formación histórica que inscribe el modo de producción y la producción, donde el objeto no es sólo producido por el sujeto sino que él produce a su sujeto. Esta última línea va a abrir en el campo de la filosofía una compleja investigación sobre el aparato estético y cómo es que el objeto transforma la percepción y, por tanto, las condiciones de experiencia del sujeto. Creemos que apuntes como los que se desarrollan en la Introducción general a la crítica política de Marx son importantes, pues marcan los problemas que todo un grupo de pensadores, incluido Benjamin, intentarán responder. 
Eagleton en La estética como ideología, devolver al cuerpo sus capacidades expropiadas. Al abolir la propiedad privada, un sentido producido por el capitalismo, podrían volver plenamente los sentidos.

Sólo cuando los impulsos corporales hayan sido liberados del despotismo de la necesidad abstracta, y el objeto haya sido restaurado, de modo similar, de la abstracción funcional hasta convertirse en un valor de uso materialmente individual, será posible vivir estéticamente. Sólo subvirtiendo al Estado seremos capaces de experimentar nuestros cuerpos. Puesto que la subjetividad de los sentidos humanos es un hecho objetivo de principio a fin, el producto de una historia material compleja, sólo a través de una transformación histórica puede emerger esa subjetividad material. ${ }^{9}$

Benjamin, cercano a la tradición marxista, también problematizará los sentidos y, por lo tanto, las condiciones de la sensibilidad en la modernidad. Para hacerlo, seguirá de cerca a Baudelaire, que en el pasear ante la multitud produce una crítica de clase que rehúye al optimismo, a la confianza, a lo real.

La sensatez nos dice que las cosas de la tierra bien poco existen, y que la verdadera realidad sólo está en los sueños. Para digerir tanto la felicidad natural como la artificial, hay que tener primero el valor de tragarla, y quizás sean precisamente quienes merecen la dicha aquellos a los que la felicidad, tal como la conciben los mortales, les ha hecho siempre el efecto de un vomitivo. ${ }^{10}$

Charles Baudelaire, "descontento de todos y descontento de sí", ${ }^{11}$ encarna el conflicto de Benjamin de conformarse con la experiencia vivida que ofrece la modernidad, del descontento de conformarse con la anestesia del sueño que ofrece la razón moderna con mitos que intentan naturalizar una realidad ya completamente desvinculada de la propia naturaleza, donde el mito sin origen posible es sólo ideología. ${ }^{12}$

${ }_{9}^{9}$ Terry Eagleton, La estética como ideología. Madrid, Trotta, 2006, p. 272.

${ }^{10}$ Charles Baudelaire, Los paraísos artificiales. Madrid, Valdemar, 2000, p. 11.

${ }^{11} \mathrm{Cf}$. Ch. Baudelaire, Las flores del mal, op. cit.

${ }^{12}$ Será importante notar el peso de la reflexión de Benjamin sobre el mito. Desde textos como el Origen del drama barroco alemán a los escritos de los Das Passagen-Werk es recurrente una crítica al mito donde explora cómo su continuidad en la modernidad genera una tensión con la verdad que sólo podrá salvarse en la destrucción. Confrontar: "The task of criticism, the, is the differentiation of truth from myth, or rather purging and clarification of the mythic element so as to intimate to the true. Benjamin's criticism 
Benjamin, al igual que Baudelaire, buscará transformar los sueños de la razón en imágenes oníricas. Baudelaire es uno de esos "bárbaros", uno de esos hombres a los que la pobreza de la experiencia los llevó a comenzar desde el principio, a construir con poquísimo y sin mirar ni a diestra ni a siniestra, ${ }^{13}$ que intentó darle, por medio de la mirada alegórica a la experiencia vivida el peso de una experiencia. La obra de Baudelaire, según la crítica que realiza Benjamin, ${ }^{14}$ permite que el hombre que se enfrenta a su poesía lírica conquiste una experiencia donde lo que emerge no es el conocimiento sino la singularidad. Este tipo de producción hace posible una experiencia de la desconfianza: de la realidad, de los valores, de la estructura misma de la experiencia. La experiencia del arte se convierte en un arte de la desconfianza que despliega la risa bárbara de los hombres que se disponen a sobrevivir a la cultura misma.

Benjamin buscó desplegar su pensamiento en estas obras, donde la función de la crítica del arte, era, cercana a sus propias investigaciones a la noción de crítica del romanticismo alemán, una manera de desplegar constelaciones de sentido donde la crítica se abría, desde la argumentación filosófica, ${ }^{15}$ como apunte urgente sobre la actualidad.

Pero Baudelaire no fue el único que buscó la otra dimensión de la realidad en las visiones oníricas y que encontró en ellas, como mandamiento, la ebriedad que permitía desconfiar de la fortaleza y estabilidad de la estructura racional del mundo. En Aragon - pero también en el surrealismo disidente de Bataille y de Klossowski-, Benjamin cimentó la búsqueda de la experiencia que permitió mostrar la imagen alegórica de la modernidad. Imagen que permite leer el sueño desde la ruina, desde la historia, desde lo que desborda y no pasa por la razón sino por el recuerdo.

is never merely interpretative or evaluative but rather expiatory and redemptive: it is an activity that "destroys" its object only to plumb it from the truth it might contain. This destructive urge is a constant: it marks the earliest and the latest comments on criticism" (Howard Eiland y W. Michael Jennings, Walter Benjamin. A Critical Life. Cambridge, Mass. /Londres, Universidad de Harvard, 2014, p. 166).

${ }^{13} \mathrm{Cf}$. W. Benjamin, "Experiencia y pobreza", en Discursos interrumpidos. Barcelona, Planeta/Agostini, 1994, p. 169.

${ }^{14}$ Es importante señalar que este texto no trata de hacer una revisión de la obra de ninguno de los autores que estudia Benjamin, sino de poder explorar su crítica de arte y entender los elementos que el filósofo propone pueden llevar a una experiencia como crítica a la modernidad.

${ }^{15}$ Aquí también es importante subrayar que la noción de crítica de arte desde la que Benjamin trabaja es cercana a la tradición abierta por Kant, donde la crítica se entiende como una investigación sobre las condiciones de posibilidad de la experiencia. Este tipo de crítica de arte, si bien no es la más común en la teoría del arte, sigue marcando una trayectoria importante que se distingue, en objetivos y metodología, de la crítica como literatura o historia del arte. 


\section{De la mercancía al surrealismo}

Al tiempo que la experiencia se empobrecía por su restricción a los límites de la reflexión, los sueños se colocaban en la mente de las colectividades como un encantamiento. Benjamin afirmó que: "El capitalismo fue un fenómeno natural con el que un nuevo sueño se derramó sobre Europa, y a través de él se reactivaron las fuerzas míticas". ${ }^{16}$ Esta cita la podemos comprender desde los planteamientos de Marx con respecto a, por un lado, la mercancía, donde el objeto sufre una transmutación "en cosa sensorialmente suprasensible rica en sutilezas metafísicas y reticencias teológicas" ${ }^{17}$ y, por el otro, a su reflexión sobre los mitos, donde en la Introducción general a la crítica política, y en relación con el arte griego, Marx confronta qué puede hacer el mito en la época del ferrocarril y del telégrafo.

Ambos momentos en Marx, lo que apuntan es a un señalamiento de la transformación de las cosas a partir de la mercancía en una representación inestable. En ella, se han reactivado las fuerzas mágicas que buscan el mito como lugar de origen para poder naturalizar las relaciones con el mundo. En la crítica de Marx, al igual que en los planteamientos de Benjamin, el arte tiene que estar acorde con la producción histórica de su tiempo. Olvidar el modo en que se producen los objetos sólo puede generar -siguiendo con la línea argumental de Marx- un infantilismo que no habrá de recuperar la infancia y, por el contrario, tendrá el problema de instalar la metafísica en el objeto. Y ésta se aparecerá en la modernidad como fantasmagoría. ${ }^{18}$ Para Benjamin, esta

${ }^{16}$ W. Benjamin, The Arcades Proyect. Cambridge, Mass. /Londres, Universidad de Harvard, 1999, (K1a, 8), p. 391.

17 Confrontar: "A primera vista, una mercancía parece ser una cosa trivial, de comprensión inmediata. Su análisis demuestra que es un objeto endemoniado, rico en sutilezas metafísicas y reticencias teológicas. En cuanto valor de uso, nada de misterioso se oculta en ella, ya la consideremos desde el punto de vista de que merced a sus propiedades satisface necesidades humanas, o de que no adquiere esas propiedades sino en cuanto producto del trabajo humano. Es de claridad meridiana que el hombre, mediante su actividad, altera las formas de las materias naturales de manera que le sean útiles. Se modifica la forma de la madera, por ejemplo, cuando con ella se hace una mesa. No obstante, la mesa sigue siendo madera, una cosa ordinaria, sensible. Pero no bien entra en escena como mercancía, se trasmuta en cosa sensorialmente suprasensible. No sólo se mantiene tiesa apoyando sus patas en el suelo, sino que se pone de cabeza frente a todas las demás mercancías y de su testa de palo brotan quimeras mucho más caprichosas que si, por libre determinación, se lanzara a bailar" (Karl Marx, El capital. México, Siglo XXI, 2001, t. I, vol. 1, p. 87).

${ }^{18}$ Confrontar: "La idea de la naturaleza y de las relaciones sociales que está en la base de la fantasía griega, y, por lo tanto, del (arte) griego, ¿es posible con los selfactors, las locomotoras y el telégrafo eléctrico? ¿A qué queda reducido Vulcano al lado de Roberts \& Co., Júpiter al lado del pararrayos y Hermes frente al Crédít mobilier? 
categoría, que fue central para su trabajo de los años treinta, señala el modo en que la mercancía capitalista presiona para generar un real que se toma como natural y dado, escondiendo que es un constructo socioeconómico.

A la luz de esta lectura de la mercancía, la operación crítica será encontrar en los objetos, en las imágenes, en la arquitectura, aquella promesa fallida y buscar, como afirma Ricardo Ibarlucía en su análisis sobre la relación entre Benjamin y el surrealismo, "el espacio donde los sueños de una época se inmovilizan inscribiendo sobre el fetiche de la mercancía 'la palabra historia con los caracteres de la caducidad'". ${ }^{19}$ Benjamin, a finales de los años veinte, escribió a Hugo von Hofmannsthal: "Mientras en Alemania me siento completamente aislado de los hombres de mi generación hay en Francia algunas manifestaciones [escritores como Giradoux y especialmente Aragon, el movimiento surrealista] en cuya obra veo aquello que también me preocupa" ${ }^{20}$ Lo que le preocupaba era cómo destruir el mito para que emergiera la historia. Sólo desde una revuelta tanto estética como epistemológica podría abrirse paso a la política.

Benjamin buscaba contraponerse a la política poética del capitalismo que apoyaba el surgimiento de los totalitarismos a través de "un mal poema de primavera lleno hasta reventar de comparaciones". ${ }^{21}$ La política del capitalismo llenaba sus discursos de metáforas que evocaban la riqueza y la libertad, con lo que, los socialdemócratas, pretendían infundir la confianza necesaria para la organización de las masas alrededor del fascismo. Ante la estetización de la política que fomentaban los movimientos fascistas con su política y con la utilización de un sistema de aparatos que mantenían el sistema de valores fundados en el culto, ${ }^{22}$ Benjamin buscaba aliados que permitieran contraponerse

Toda mitología somete, domina, moldea las fuerzas de la naturaleza en la imaginación y mediante la imaginación y desaparece por lo tanto con el dominio real sobre ellas, ¿en que se convierte Fama frente a la Printing house square? El arte griego tiene como supuesto la mitología griega, es decir, la naturaleza y las formas sociales ya modeladas a través de la fantasía popular de una manera inconscientemente artística. Éste es su material" (K. Marx, Introducción general a la crítica de la economía política. México, Siglo XXI, 1989, p. 61).

${ }^{19}$ Ricardo Ibarlucía, Onirokitsch: Walter Benjamin y el surrealismo. Buenos Aires, Manantial, 1998, pp. 67-68.

${ }^{20}$ Ibid., p. 15.

${ }^{21}$ W. Benjamin, "El surrealismo. La última instantánea de la inteligencia europea", en Imaginación y sociedad. Iluminaciones I. Madrid, Taurus, 1998, p. 19.

${ }^{22}$ El trabajo de la cineasta alemana Leni Riefensthal se vuelve un ejemplo claro de cómo el fascismo hizo una estetización de la política donde, por un lado, se utilizaba el sistema de aparatos desde una función cultural para resaltar la figura del dictador, como sucede en El triunfo de la voluntad (1935). Y, por el otro, cómo se utiliza ese mismo aparato para producir la representación de la masa y su sometimiento ideológico, como en el caso de Olympia (1938). 
a estos movimientos para acceder al puro ámbito de lo político expulsando toda metáfora moral. Benjamin necesitaba de la imagen pura, sin censura, de la conciencia, necesitaba la ebriedad y la dislocación de la modernidad, y esto lo encontró en el surrealismo.

El surrealismo para nuestro autor no era un movimiento artístico que mantuviera la alianza de clases, sino siguiendo con algunas propuestas de la vanguardia, se trataba de: "manifestación, de consigna, de bluff, de falsificación si se quiere, pero sobre todo no de literatura". ${ }^{23}$ El surrealismo, a partir de un inventario psíquico, presentó los sueños y los objetos sin interpretarlos, con el propósito de reunir los materiales para la configuración de una fenomenología onírica que permitiera una revolución a la idea moderna de hombre. El verdadero fin del surrealismo, nos dice Ibarlucía, "no era la de producir obras de arte sino enfrentar las consecuencias de este cambio profundo en las relaciones entre el sujeto y el mundo de objetos de la técnica”. ${ }^{24}$ El surrealismo, como movimiento, pretendió enfrentar el empobrecimiento de la experiencia a partir de la perversión, en el sentido de su cuestionar la costumbre y orden habitual de las cosas. ${ }^{25}$

A través de la escritura automática, el hipnotismo y el uso de drogas, el surrealismo encontró otra vía de acceso a aspectos cruciales de la conciencia moderna que permitieran fisurar no sólo la razón sino la naturalización -el mito- que se escondía en las cosas. El surrealismo buscaba la experiencia donde "la vida parecía que sólo merecía la pena de vivirse, cuando el umbral entre la vigilia y el sueño quedaba desbordado como por el paso de imágenes que se agitan en masa". ${ }^{26}$ La búsqueda del surrealismo estaba en encontrar una imagen que tuviera precedencia al sentido, y la encontraron en la imagen onírica.

Para la producción de esta imagen onírica es interesante el peso que pudieron tener las drogas como acceso a una percepción distorsionada. Ciertamente, Baudelaire, los surrealistas y el propio Benjamin buscaron, principalmente en el hachís, una manera de romper con la razón para acceder a una percepción más viva de las cosas, para tener una experiencia que debilitara la censura de la conciencia limitada por la tradición, sin embargo, las drogas no son, para estos autores, el acceso a una embriaguez prodigiosa que abre las puertas a un mundo extraño y trastornado. Baudelaire afirma que:

${ }^{23}$ W. Benjamin, "El surrealismo. La última instantánea de la inteligencia europea", en op. cit., p 45.

${ }^{24}$ R. Ibarlucía, op. cit., p. 55.

${ }^{25}$ Esta noción de perversión como cuestionamiento del orden es muy importante no sólo para los planteamientos de Bataille, quien encontrará en el erotismo y la violencia un modo de crítica al sujeto.

${ }^{26}$ W. Benjamin, "El surrealismo. La última instantánea de la inteligencia europea", en op. cit., p. 45. 
[...] no encontrarán en el hachís nada milagroso, absolutamente nada más que lo natural en exceso. El cerebro y el organismo sobre los que el hachís opera no provocarán sino fenómenos cotidianos, individuales, aumentados, ciertamente, en cuanto número y energía, pero siempre fieles a su origen. El hombre no escapará a la fatalidad de su temperamento físico y moral: el hachís será, para las impresiones y los pensamientos familiares del hombre, un espejo de aumento, pero un puro espejo. ${ }^{27}$

Benjamin aseguraba que el comedor de opio era un iluminado, y esto es porque las drogas permiten ver más, porque la percepción se modifica, sin embargo, las drogas no son, según nuestro autor, sino la escuela primaria de la iluminación. En sentido estricto, éste será el concepto que permitirá acercar la imagen onírica a la emancipación. Si bien, en los argumentos trazados por Benjamin es importante cuestionar y modificar la percepción su punto de inflexión estará en la experiencia del pensamiento.

La noción de iluminación profana es ciertamente un oxímoron, ya que la palabra iluminación alude a la revelación de corte místico, mientras que la palabra profana significa tanto terrenal como mundana. Con ella, Benjamin quiere garantizar que la conquista del pensamiento que ilumina desde la oscuridad, no está restringido al éxtasis religioso ni al de estupefacientes, pues para Benjamin: "el lector, el que piensa, el holgazán, el flâneur, son tipos de iluminados al igual que el consumidor de opio, el soñador, el extasiado. Y más profanos. Para no hablar de la más terrible de las drogas -nosotros mismosque tomamos en soledad". ${ }^{28}$

La iluminación profana es un concepto necesario para no quedarse en la ebriedad que provocan las imágenes, para no quedarse inmerso en las fantasmagorías. Aquel que se "ilumina" gana fuerzas de la ebriedad para transformar ésta en acción. La iluminación profana es la que permite llevar la revuelta de la embriaguez a la revolución, revolución que no implica, o no solamente, una transformación en las condiciones de producción, sino una revuelta en la comprensión. Ésta necesariamente supondría una ruptura con alienación que produce el mundo encantado por una técnica al servicio de un pensamiento que mantiene el culto y la naturalización como formas de sometimiento.

El surrealismo estaba en el centro de la embriaguez, pero según lo señalaba Benjamin, siempre se encontró bajo el peligro de ser seducido por su propia herencia esteticista y confundir la euforia revolucionaria con la praxis

${ }^{27}$ Ch. Baudelaire, Los paraísos artificiales, p. 25.

${ }^{28} \mathrm{~W}$. Benjamin, Surrealism, en http://www.generation-online.org/c/fcsurrealism. htm. [Consulta: 12 de enero de 2014.] 
política genuina. La crítica del movimiento, más que apuntar un abandono del espíritu de la revuelta, lo que propone es ganar fuerzas de su intoxicación para la revolución. Benjamin en su crítica a los surrealistas muestra cómo el en-sueño y la embriaguez que provoca caminar fuera de la razón no es suficiente para la transformación. Conquistar la ebriedad para la revolución era un paso necesario que tenía que ganar la revuelta surrealista, y esta conquista implicaba oponerse al tipo de experiencia -alienada y de autocontemplación en la masa- que propugnaba el fascismo, y suponía acercarse a la respuesta comunista sobre la relación entre la política y la moral, lo cual significaba: "Pesimismo en toda la línea. Así es y plenamente. Desconfianza en la suerte de la literatura, desconfianza en la suerte de la libertad, desconfianza en la suerte de la humanidad europea, pero, sobre todo desconfianza, desconfianza en todo entendimiento: entre las clases, entre los pueblos, entre éste y aquél". ${ }^{29}$

Benjamin desconfiaba del optimismo de los socialdemócratas, y ésta era la única manera de salvarse de la anestesia que provocaba el discurso lleno de optimismo. La única manera de contraponer la confianza que cegaba a los hombres con la promesa del progreso era desconfiar de él; la única manera de no caer presa de los fanatismos totalitarios era desconfiar, y Benjamin hace de su pensamiento un arte de la desconfianza. En su desconfianza, ve en el surrealismo un pesimismo que se opone al sueño del progreso, que vuelve su rostro hacia la existencia surrealista de la realidad. El surrealismo, así como el comunismo, organizaba el pesimismo, y esto para Benjamin no significaba caer en un nihilismo que negara toda posibilidad de acción positiva.

La organización de la desconfianza en Benjamin tiene un objetivo: "expulsar la metáfora moral de la política para descubrir en la acción política una esfera reservada cien por ciento para las imágenes" ${ }^{30}$ La desconfianza permite que:

En el insulto, en el malentendido, allí donde una acción sea ella misma la imagen, la establezca de por sí, la arrebate y la devore, donde la cercanía se pierda de vista, es donde se abrirá el ámbito de imágenes buscado, el mundo de actualidad integral y polifacética en el que no hay "aposento noble", en una palabra, el ámbito en el cual el materialismo político y la criatura física comparten al hombre interior, la psique, el individuo (o lo que nos dé más rabia) según una justicia dialéctica (esto es, que ni un solo miembro queda sin partir). Pero tras esa destrucción

${ }^{29}$ W. Benjamin, "El surrealismo. La última instantánea de la inteligencia europea", en op. cit., p. 60.

${ }^{30}$ La traducción del texto en español nos pareció confusa, así que optamos por la edición en inglés. W. Benjamin, "Surrealism", en One-Way Street. Londres, Verso, 2000, p. 238. La expulsión de la moral que propone Benjamin debe leerse como esa moral que mezclaba el fascismo en su discurso político a través de la estetización de la política. 
dialéctica el ámbito se hace más concreto, se hace ámbito de imágenes: ámbito corporal. ${ }^{31}$

La desconfianza destruye la metáfora moral que envuelve el ámbito político instaurado por el fascismo en su estetización de la política, destruye ese halo de cercanía y de culto con las que el fascismo quiso conquistar la confianza de la sociedad para su proyecto totalitario. La desconfianza expulsa la moral y posibilita el despertar. Un despertar en una experiencia psíquica y corpórea en el individuo, en la colectividad. Benjamin afirma que: "[...] cuando cuerpo e imagen se interpretan tan hondamente, que toda tensión revolucionaria se hace excitación corporal colectiva y todas las excitaciones corporales de lo colectivo se hacen descarga revolucionaria, entonces y sólo entonces, se habrá superado la realidad tanto como el Manifiesto Comunista exige". ${ }^{32}$

\section{El interior del sueño: los pasajes}

Las imágenes oníricas para Benjamin no sólo son una excitación nerviosa en la que aflora la psique reprimida de un individuo. Este tipo de representaciones para Benjamin, sugiere Ibarlucía, "no es un fenómeno intemporal, naturalmente dado en el hombre, sino una forma de experiencia históricamente construida. Los sueños están inmersos en la historia: su forma, contenido y función difieren según la época a la que pertenecen". ${ }^{33}$

Benjamin escribió en 1925 un pequeño texto conocido como Onirokitsch, en él Benjamin asegura que: "La historia del sueño aún está por escribirse, y abrir una perspectiva en ella significaría asestar un golpe decisivo a la superstición de su encadenamiento a la naturaleza mediante una iluminación histórica. El soñar participa de la historia”. ${ }^{34}$ En este texto, Benjamin quiere dejar claro que "el sueño ya no abre la azul lejanía", 35 como lo hizo para Novalis y Jean Paul, en su tiempo, el sueño abre el camino a la banalidad y lo hace porque su tiempo es, de hecho, banal. Una historia del sueño ${ }^{36}$ establecería aquello que ha sido reprimido por los hombres, significaría un inventario de los obje-

${ }^{31}$ W. Benjamin, "El surrealismo. La última instantánea de la inteligencia europea", en op. cit., p. 61.

${ }^{32}$ Ibid., p. 62.

${ }^{33}$ R. Ibarlucía, op. cit., p. 29.

${ }^{34}$ W. Benjamin, "Onirokitsch", en R. Ibarlucía, op. cit., p. 111.

35 Idem.

${ }^{36}$ Es interesante notar la construcción e importancia del sueño en la época. Como señala Didi-Huberman en Supervivencia de las luciérnagas, hubo en Alemania un caso muy interesante. Entre 1933 y 1939 Charlotte Bernard recogió los sueños de la gente para producir "un documento psíquico del totalitarismo, del terror político en cuanto 
tos que conforman la cotidianidad del hombre, esos que durante la vigilia, y por la protección de la conciencia contra los estímulos, pasan desapercibidos pero que en el en-sueño aparecen, revelando el impacto que tuvieron en el individuo. Las imágenes oníricas no son tratadas por Benjamin en su origen psicológico, sino en relación con las advertencias proverbiales - presagios, presentimientos y señales- que se dirigen sobre el mundo de la vigilia. ${ }^{37}$ En los sueños, como había dicho Baudelaire, aparecen los objetos con los que se encuentra el hombre durante su jornada, pero el objeto en este estado se transforma completamente.

Desde esta fundamentación se revoca la imagen externa de las cosas, y si se anula lo externo, ¿qué lado ofrece el objeto al sueño? Benjamin afirma que: "Es el lado desteñido por el hábito y adornado baratamente de frases hechas. El lado que la cosa ofrece al sueño es el kitsch". ${ }^{38}$

En la fenomenología onírica lo que emerge en el sueño es el mundo de objetos de la técnica cuya quintaesencia es el kitsch. Este término, nos dice Ibarlucía, viene de kitschen que en español significa "chapucear" o "farfullar", y de la palabra en alemán kitsch que significa "baratija", "imitación" o "cursilería". El kitsch, por tanto, designa toda manifestación de "mal gusto", cultivada o no, en arte, cine, publicidad, moda, mobiliario y objetos cotidianos. El objetivo básico del kitsch es la estetización, lo decorativo, el efecto bello. En ella podemos entender esa sublimidad "mala", como lo expone Marx en su crítica a la mercancía, donde lo que se establece, en palabras de Eagleton es "una cadena metonímica imparable en la que un objeto se refiere a otro y éste a otro, hasta el infinito". ${ }^{39}$ En este objeto se subvierte toda representación estable y lo que se pasma es la propia capacidad de representación del sujeto.

Ante el objeto "endemoniado" de la mercancía, el surrealismo crea una obra dépaysé, ahí la desorientación saca a las cosas de su marco familiar y las traslada a otro no habitual, siniestro. La mirada surrealista saca al objeto de la singular fundamentación de las cosas como útiles, y pasa a segundo plano su valor de uso. Despojadas de su valor de uso, las cosas no resultan más que notas recordatorias de aquellos objetos sobre los cuales, en otro tiempo, se ha posado el deseo.

Del mundo siniestro de las cosas, que aparece en Baudelaire y en las imágenes oníricas de los surrealistas, emerge el más soñado de sus objetos, la misma ciudad de París. Benjamin afirma que tenía que ser París, donde los muros,

proceso obsesivo -obsesionante- hasta en lo más profundo de las almas" (Georges Didi-Huberman, Supervivencia de las luciérnagas. Madrid, Abada, 2012, p. 104). Es decir, el sueño - en los varios sentidos que tomó en la época- fue un espacio en el que pareció abrirse una crítica a su tiempo.

${ }^{37}$ R. Ibarlucía, op. cit., p. 79

${ }^{38}$ Ibid., p. 112.

${ }^{39}$ T. Eagleton, op. cit., p. 284. 
los muelles, el asfalto, las colecciones, los escombros, las verjas, las plazas, los pasajes y los quioscos enseñan, en ese mundo objetivo, que las relaciones humanas alcanzan la profundidad de un sueño. Ahí está esperando la visión que revelará el auténtico rostro, el surrealista.

En el trabajo que realiza sobre los surrealistas descubre un mundo de objetos que constituyen y conforman la existencia del hombre moderno, descubre un mundo de fantasmagorías en la que los objetos se convierten en símbolos del deseo, de los ideales. Descubrir el sueño monumental del siglo XIX y leerlo desde el rostro alegórico, surrealista, donde se debilita el mito y emerge la historia desde la ruina es para Benjamin la única manera de despertar de él.

En el interior de las fantasmagorías se abren los pasajes y el pensamiento encuentra su prehistoria. Desde el año de 1927 Benjamin ideó una investigación que correría paralelamente a todas sus preocupaciones, el proyecto fue llamado Passagen-Werk, en él buscaría expresar el sentimiento de vértigo que caracterizó la concepción de la historia del siglo XIX, y que "corresponde a un punto de vista de acuerdo al cual el curso del mundo es una serie infinita de hechos congelados en la forma de cosas". ${ }^{40}$ Por eso, Benjamin va a buscar el carácter expresivo de los primeros productos industriales, de las primeras construcciones en hierro, de las primeras máquinas, de las primeras tiendas y afiches, es decir, de los objetos con los que la modernidad dominó al mundo con sus fantasmagorías. El proyecto de los Pasajes acompañó a Benjamin más de diez años, éste se convirtió en su proyecto más grande y esperado por todos sus allegados. ${ }^{41}$

Los Passagen-Werk es un trabajo de montajes, un trabajo que recoge los sueños monumentales de la razón que se manifiestan en los objetos y que hereda la mirada de los surrealistas. ${ }^{42}$ Benjamin sostenía que "la filosofía no sólo

${ }^{40}$ W. Benjamin, "Exposé of 1939", en op. cit., p. 14.

${ }^{41}$ Mucho se ha especulado sobre la suerte de este texto, se cuenta que en septiembre de 1940, cuando Benjamin trataba de escapar de Francia por la ruta de los Pirineos, éste cargaba un portafolios en el que él mismo aseguraba se encontraba un trabajo que resultaba más importante que llegara a Estados Unidos que su propia vida. Tras su suicidio en la ciudad de Port-Bou, en septiembre de 1940, y ante el inminente fracaso de su escapatoria, el portafolio desapareció y nadie sabe si en él se encontraba una versión definitiva o terminada de los Pasajes. Sin embargo, algo queda del imposible trabajo de Benjamin, lo que se conoce como Passagen-Werk fueron los manuscritos que Benjamin dejó escondidos en la Biblioteca Nacional de París y que salieron a la luz, gracias a Georges Bataille, mucho tiempo después del final de la Segunda Guerra Mundial.

${ }^{42}$ Sin esta herencia surrealista sería imposible establecer la mirada onírica que Benjamin le imprime a los objetos, que como tales son el resultado de los sueños voluntarios y reflexivos del siglo XIX. El que Benjamin afirme que la filosofía debe ser ella misma surrealista nos permite interpretar su exposición de los sueños como una búsqueda de la experiencia no controlada de la que emerge lo fallido de la historia, 
debía recoger el surrealismo, sino ser surrealista ella misma". ${ }^{43}$ Y esto quiere decir buscar el estrato onírico de las cosas, ya que éste permite ver, en la relación con la técnica, una historia no natural sino el producto de las condiciones históricas. Esta lectura no deja aposento noble, y lo que emerge es la historia que había sido sepultada por la fantasmagoría del progreso. Adorno afirmó que Benjamin, con el trabajo de los Pasajes, "pensaba construir la idea de una época, en el sentido de una prehistoria de la modernidad". ${ }^{44} \mathrm{El}$ argumento que parece delinearse en el texto de los Passagen, según señala Ibarlucía, es que: "por debajo de una racionalización creciente, articulado a un nivel onírico inconsciente, el mundo social ha sido plenamente re-encantado. En la ciudad moderna, que el flâneur surrealista recorre como un sonámbulo, el 'amenazador y fascinante' rostro del mito le sale al encuentro en todas partes". ${ }^{45}$

Benjamin demuestra con la captura los sueños monumentales del siglo XIX, a partir de las imágenes que dejaron grabadas en la fisonomía del siglo xx, que la modernidad no expulsó al mito con la razón sino que lo ocultó en los ideales. El mito para Benjamin emerge en las arcadas, en esas construcciones que fueron el sueño del capitalismo en las que las mercancías están suspendidas y amontonadas entre sí en tan estrecha confusión que parecen sacadas de los en-sueños más incoherentes. La ciudad se abre en las arcadas como un paisaje primitivo de consumo. Lo que Benjamin quiere anunciar es que la cultura de masas moderna encuentra, en la divinización de los poderes de la técnica, su correspondencia con el mundo simbólico de los mitos. Y aquí está el peligro, el hombre ha construido su realidad sobre la base de los ideales de la razón que se manifiestan en los sueños de progreso que despiertan las fuerzas míticas, aunque estás sean negadas en su propia estructura racional.

La captura de las imágenes del siglo XIX en los Passagen no tiene como intención la creación de un museo para ver lo que ha sido, Benjamin está buscando la imagen dialéctica para romper con la ilusión. Las imágenes que permiten ir más allá de la desconfianza y generar una nueva comprensión son

en la que surge el acontecimiento no desde lo vivido por la reflexión sino desde el recuerdo, desde la huella. Sabemos que nuestra interpretación es arriesgada, que la relación entre el sueño como resultado de la reflexión y el sueño como visión onírica resultado de una experiencia no controlada es susceptible de confusión. Lo que aquí intentamos rastrear es en qué sentido puede ser la filosofía surrealista, cómo este ser modifica la mirada. Sabemos que ésta no es la interpretación "habitual" de los sueños, sin embargo, parece un puente interesante del porqué de la búsqueda de los sueños y, sobre todo, de cómo despertar de ellos. Tampoco queremos reducir a Benjamin a esta visión, ésta es sólo una interpretación posible que esperamos arroje luz o permita pensar lo ya dicho de otro modo.

43 Theodor Adorno, Sobre Walter Benjamin. Madrid, Cátedra, 1995, p. 24.

${ }^{44}$ Idem.

${ }^{45}$ R. Ibarlucía, op. cit., p. 66. 
las imágenes del recordar, del en-sueño que embriagan y que permiten ganar fuerzas para la revolución, para el giro copernicano del recordar que nos permite darnos cuenta, que permite iluminar, es decir pensar. La iluminación de Benjamin permite despertar del sueño del pasado y posibilita el encuentro con un pasado no de lo que ha sido, sino con el pasado de lo que es en el ahora de la cognoscibilidad.

\section{Conclusión}

Si Benjamin busca la imagen dialéctica es porque para él: "acordarse y despertarse son estados que están íntimamente ligados. Despertarse es, a saber, el dialéctico giro copernicano del recuerdo". ${ }^{46}$ Despertar es un proceso gradual, que existe tanto en la vida del individuo como en la vida de las generaciones, del cual el dormir es el estado inicial. El siglo xx, para Benjamin, estaba dormido y había que despertarlo y, para ello, tenía que recordar. ${ }^{47}$ El pasado para esta generación empobrecida se convirtió en un mundo de infancia que quedó aislado y disperso. Lo que Benjamin pretende hacer en sus Pasajes es un "experimento en la técnica del despertar. Un intento de caer en cuenta (become aware) del dialéctico-copernicano-giro del recordar", ${ }^{48}$ donde la política alcanza primacía sobre la historia.

Formalmente se ha pensado que un punto fijo ha sido encontrado en "lo que ha sido", y uno veía el presente comprometido, concentrando las fuerzas del conocimiento, en este suelo. Ahora esta relación va a ser volteada y, lo que ha sido se convertirá en el reverso dialéctico -el flash de la conciencia despertada. La política alcanza primacía sobre la historia. Los hechos se convierten en algo que nos pasa por primera vez, que por primera vez nos golpean; de hecho, despertarse es el mejor ejemplo de la memoria: la ocasión que nos es dada para recordar lo más cercano, lo gastado, lo más obvio. ${ }^{49}$

${ }^{46}$ W. Benjamin, The Arcades Project, (K1, 3), p. 389.

${ }^{47}$ Aunque por motivos de espacio no podemos analizar y relacionar las reflexiones que emergen en la crítica al trabajo de Proust es importante señalar que las nociones del recordar y el proceso que éste tiene en la subjetividad y en la temporalidad son planteados por Benjamin en la crítica al autor de En busca del tiempo perdido. No será sólo el famoso pasaje de la magdalena el que le permitirá a Benjamin pensar en la potencia de los sentidos para el recuerdo involuntario, sino que también el propio análisis de la subjetividad burguesa le permitirá una crítica de clase para, justamente desarrollar, la dialéctica entre el recuerdo y el despertar.

${ }^{48}$ W. Benjamin, The Arcades Project, $(\mathrm{K} 1,1)$, p. 388.

${ }^{49}$ Ibid., (K1, 2), pp. 388-389. 
Recordar para Benjamin supone la posibilidad de renovar las fuerzas del pasado, en no considerar lo sucedido como algo lejano que ya no afecta, el recordar el pasado como se recuerda en el despertar garantiza volver a ser golpeado por él, reencontrar el pasado no desde el pasado sino desde el propio presente.

Y no es que el pasado encuentre su significado en lo que está presente, o lo que está presente encuentre su sentido en lo que es pasado, más bien, es la imagen en la que lo que ha sido se junta, en un flash, con el ahora para formar una constelación. La imagen del pasado que entra en el mundo de semejanza con el presente se convierte para Benjamin en la imagen dialéctica. La relación del pasado con el presente no es progresiva sino que se detiene en la imagen que de pronto emerge. Para Benjamin, sólo las imágenes dialécticas son genuinas, esto es, no arcaicas, y éstas evocan el recuerdo que despierta. Para Benjamin, "cada día presente es determinado por las imágenes que le son sincrónicas: cada 'ahora' es el ahora de una recognoscibilidad particular". 50

El pensamiento de Benjamin exploró la posibilidad de una experiencia que permitiera salir de la alienación de los sentidos que el capitalismo había generado. Desde la crítica a la mercancía, Benjamin generó una iluminación profana de fantasmagoría, lo que de golpe, pensaba, rompía el mito para que emergiera la historia. La experiencia, desde este objeto desencantado, no sólo permitía ver el modo de producción sino que, la disolución de la promesa, producía una suerte de intoxicación y revuelta. Con ello, el objeto era devuelto a la historia y la política se abría como necesidad en una experiencia desencantada.

Si bien, la crítica a la técnica permitió a Benjamin pensar el tipo de operación que realizaba en fascismo con la estetización de la política, también le proporcionó un análisis de la transformación en la sensibilidad y, por lo tanto, de las condiciones del aparecer tanto del objeto como del sujeto. Ahí ciertas producciones artísticas pudieron intervenir en provocar una experiencia de emancipación. Con ello, lo que podemos concluir es que Benjamin, al retomar ciertos aspectos de la Ilustración y de la crítica marxista, puso en cuestión formas de la experiencia de la modernidad. Estos planteamientos, todavía, permiten problematizar a la estética para pensar en cómo el arte interviene políticamente. Su crítica del arte todavía nos invita a trabajar en problematizar la experiencia y en entender que la estética, en tanto que condición de posibilidad de ésta, sigue siendo uno de los campos de batalla para pensar lo político.

${ }^{50}$ Ibid., (N3, 1), p. 463. 